\title{
Pharmacological Properties of Geraniol - A Review
}

\author{
Authors \\ Yu Lei ${ }^{1 *}$, Peng Fu ${ }^{2 *}$, Xie Jun ${ }^{1}$, Peng Cheng ${ }^{1}$ \\ Affiliations \\ 1 School of Pharmacy, Chengdu University of Traditional \\ Chinese Medicine, Chengdu, China \\ 2 West China School of Pharmacy, Sichuan University, \\ Chengdu, China \\ Key words \\ geraniol, essential oil, pharmacology, monoterpene \\ received August 1, 2018 \\ revised September 6, 2018 \\ accepted September 18, 2018 \\ Bibliography \\ DOI https://doi.org/10.1055/a-0750-6907 \\ Published online October 11, 2018 | Planta Med 2019; 85: \\ 48-55 @ Georg Thieme Verlag KG Stuttgart · New York I \\ ISSN 0032-0943 \\ Correspondence \\ Prof. Peng Cheng \\ School of Pharmacy, Chengdu University of Traditional \\ Chinese Medicine \\ 37 Shierqiao Road, Jinniu District, 611137 Chengdu, China \\ Phone: + 8602861800018 , Fax: + 8602861800018 \\ pengchengchengdu@126.com
}

\begin{abstract}
Geraniol is an acyclic isoprenoid monoterpene isolated from the essential oils of aromatic plants including Cinnamomum tenuipilum, Valeriana officinalis, and several other plants. The limited source of geraniol from plant isolation cannot fulfill the great demand from the flavor and fragrance industries, which require maximizing geraniol production through biotechnology processes. The diverse activities of geraniol suggested that geraniol could treat various diseases as a promising drug candidate. In order to evaluate the potential of geraniol applied in a clinical trial, this review aims at providing a comprehensive summary of the pharmacological effects of geraniol. The publications retrieved from PubMed, ScienceDirect, Springer, and Wiley databases were collected and summarized for the last 6 years. Then, the potential application of geraniol as a drug is discussed based on its pharmacological properties, including antitumor, anti-inflammatory, antioxidative, and antimicrobial activities, and hepatoprotective, cardioprotective, and neuroprotective effects. Hence, this review aims at providing evidence of the pharmacological activities of geraniol in the context of further development as a drug candidate in clinical application.
\end{abstract}

\section{Introduction}

GE ( $\triangleright$ Fig. 1), an acyclic isoprenoid monoterpene, can be extracted from the essential oils of several aromatic plants, such as Cinnamomum tenuipilum Kosterm (Lauraceae), Valeriana officinalis L. (Caprifoliaceae), Phyla scaberrima (Juss. ex Pers.) Moldenke (Verbenaceae), and Perilla frutescens var. hirtella (Nakai) Makino (Lamiaceae) [1]. GE has been widely used in the flavor and fragrance industries in the past decades. However, the limited production of GE via plant extraction restrains market growth. Thus, several studies are aimed at identifying an effective method to biosynthesize GE.

GE production maximization was achieved in Escherichia coli engineered to express GE synthase and with the YjgB mutation, resulting in an increase in geranyl diphosphate and prevention of GE dehydrogenation, yielding $183 \mathrm{mg} / \mathrm{L}$ in 2014 [2]. GE production was further improved during both autotrophic and heterotrophic growth in engineered Methanococcus maripaludis with cloned GE synthase from sweet basil Ocimum basilicum and the absence of puromycin, reaching $4.6 \mathrm{mg} / \mathrm{g}$ of dry weight [3].

Finally, the highest production of GE was obtained in Saccharomyces cerevisiae with GE synthase and arnesyl diphosphate synthase expression, reaching a yield of $1.68 \mathrm{~g} / \mathrm{L}$ in 2017 [4].

Recently, GE was shown to possess various pharmacological properties, including antioxidant [5], anti-inflammatory [6], antimicrobial [7], and antitumor activities [8], through multiple signaling pathway regulation in diverse biological processes, suggesting that GE is a promising drug candidate. To provide novel insights and support the clinical use of GE, we summarize the pharmacological activities of GE based on PubMed, ScienceDirect, Springer, and Wiley database searches. The scientific literature published in the years 2013 to 2018 was searched. However, several papers published before 2013 were also included for insight in the introduction and explanation. We used GE either alone or combined with antioxidant, anti-inflammatory, antimicrobial, antitumor, hepatoprotective, cardioprotective, and neuroprotective as the key words for the literature searches. Ini-

* These two authors contributed equally to this work. 


$\begin{array}{ll}\text { ABBREVIATIONS } \\ \text { 4NQO } & \text { 4-nitroquinoline-1-oxide } \\ \text { ACR } & \text { acrylamide } \\ \text { AD } & \text { atherogenic diet } \\ \text { ALT } & \text { alkaline phosphatase } \\ \text { AST } & \text { aspartate aminotransferase } \\ \text { CUMS } & \text { chronic unpredictable mild stress } \\ \text { DMBA } & \text { 7,12-dimethylbenz[a]anthracene } \\ \text { DSS } & \text { dextran sulfate sodium } \\ \text { GE } & \text { geraniol } \\ \text { GSH } & \text { glutathione } \\ \text { GST } & \text { glutathione S transferase } \\ \text { HMGCR } & \text { 3-hydroxy-3methylglutaryl coenzyme A } \\ & \text { reductase } \\ \text { iNOS } & \text { inducible nitric oxide synthase } \\ \text { LCAT } & \text { lecithin cholesterol acyl transferase } \\ \text { LDL } & \text { low-density lipoprotein } \\ \text { LPO } & \text { lipid peroxidation } \\ \text { MAPK } & \text { mitogen-activated protein kinase } \\ \text { MetS } & \text { metabolic syndrome } \\ \text { MPTP } & \text { 1-methyl-4-phenyl-1,2,3,6-tetrahydropyridine } \\ \text { mRNA } & \text { messenger ribonucleic acid } \\ \text { MS } & \text { metabolic syndrome } \\ \text { NF-KB } & \text { nuclear factor kappa-B } \\ \text { Nrf2 } & \text { nuclear factor E2-related factor 2 } \\ \text { PCNA } & \text { proliferating cell nuclear antigen } \\ \text { PD } & \text { Parkinson's disease } \\ \text { PH } & \text { partial hepatectomy } \\ \text { PTEN } & \text { phosphatase and tensin homolog deleted } \\ \text { RPA } & \text { on chromosome ten } \\ \text { VEGF } & \text { reactive oxygen species } \\ \text { SCI } & \text { spinal cord injury } \\ \text { STZ } & \text { streptozotocin } \\ \text { trinitro-benzene-sulfonic acid } \\ \text { very-low-density lipoprotein }\end{array}$

tially, 1569 research papers were selected from with the above search strategy using a ScienceDirect database search. Only 944 English written original articles about pharmacological effects and production of GE were included, refined by the Wiley database. Articles also in the PubMed database or Springer database were collected in advance. Duplicate articles were excluded and articles with similar results were also excluded. Only 72 articles were finally included after reading the titles, abstracts, and whole papers ( $\triangleright$ Fig. 2 ).

\section{Cytotoxic and Antitumor Activities}

GE exerted cytotoxic and antitumor activities on various types of cancers ( $\triangleright$ Table $\mathbf{1}$ ). Colon cancer ranks as the fourth leading cause of cancer mortality worldwide [9]. A recent study demonstrated that GE could significantly inhibit cell growth in the colon

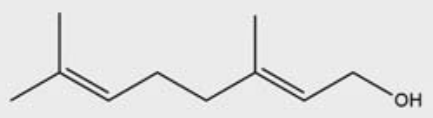

- Fig. 1 The chemical structure of geraniol using ChemBioDraw.

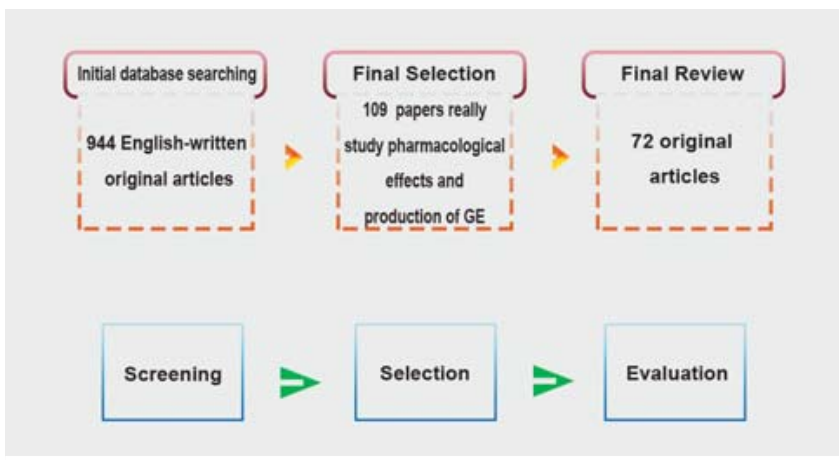

- Fig. 2 Criteria in this review for article searches and selection.

cancer cell line colo-205 with an IC 50 value of $20 \mu \mathrm{M}$. DAPI staining indicated that GE induces apoptosis, and a Western blot assay confirmed that GE upregulates Bax and downregulates Bcl-2. Bax is a pro-apoptosis regulator and $\mathrm{BCl}-2$ is an anti-apoptosis regulator. Additionally, GE induces DNA damage and cell cycle arrest in colo-205 cells [10]. Endometrial carcinoma is a common cancer among women worldwide [11]. It is worthwhile to search for novel drug candidates to treat endometrial carcinoma. Recent research showed that GE treatment and pretreatment could suppress endometrial carcinoma by inhibiting oncogenes and activating tumor suppressor genes in a female Wistar rat model induced by $\mathrm{N}$-methyl-N'-nitro- $\mathrm{N}$-nitrosoguanidine at $150 \mathrm{mg} / \mathrm{kg}$. The suppression effect of GE was more effective in the pretreatment group. Real-time PCR results show that GE inhibits the transcription of K-ras, MAPK, PI3K, and $\beta$-catenin, and Western blot results show that GE increases phosphatase and PTEN, progesterone receptors, and E-cadherin protein expression. MAPKs includes JNK, p38, and ERKs [12]. K-ras, MAPK, PI3K, and $\beta$-catenin are oncogenes, and PTEN, progesterone receptors, and E-cadherin are tumor suppressive genes [13]. The endothelioma cell line eEND2 isolated from hemangiomas easily develops angiogenesis [14]. A recent study exerted that GE showed an anti-angiogenesis effect on the endothelioma cell line eEND2. GE inhibits the migratory activity of endothelial-like eEND2 cells, along with inhibition of PCNA expression. Furthermore, GE can block the transduction of the VEGF/VEGFR-2 signal. VEGF promotes angiogenesis in cancer cells. The effect on angiogenesis was verified in vivo: GE administration to BALB/c mice reduces the number of Ki67-positive cells and CD31-positive microvessels through attenuating VEGFR2 expression [15].

Primary liver cancer is the third leading cause of cancer death worldwide [16]. Pure compounds isolated from natural products 
- Table 1 The cytotoxic and antitumor activities of GE.

\begin{tabular}{|l|l|l|l|l|}
\hline Cancer type & Suppressive effect & Cellular processes & Function study & Reference \\
\hline Colon cancer & Anti-proliferation & Apoptosis, DNA damage, and cell cycle arrest & In vitro & [10] \\
\hline Endometrial carcinoma & Anti-migration & Antiangiogenesis & In vitro and in vivo & {$[15]$} \\
\hline Liver cancer & Anti-proliferation & Apoptosis & In vitro and in vivo & {$[17-19]$} \\
\hline Lung cancer & Anti-proliferation & Apoptosis & In vitro & {$[21]$} \\
\hline Pancreatic cancer & Anti-proliferation & Apoptosis & In vitro \\
\hline Prostate cancer & Anti-proliferation & Cell cycle arrest & In vitro & {$[26]$} \\
\hline Skin cancer & Anti-proliferation & Apoptosis & In vivo & {$[28]$} \\
\hline
\end{tabular}

exerted a cytotoxic effect on liver cancer cells. In Hep-G2 hepatic cells, GE exerts an inhibitory effect by promoting apoptosis. Also, GE inhibits HMGCR protein and mRNA expression, leading to a cholesterogenesis decrease [17]. Regarding an effect of GE on hepatic cell proliferation, GE significantly inhibits Hep-G2 proliferation at a concentration as low as $5 \mu \mathrm{g} / \mathrm{mL}$ [18]. Also, GE shows an inhibitory effect on diethylnitrosamine-associated hepatocarcinogenesis after a 12-week treatment, as shown by the reduction of AST and ALT levels in serum. Additionally, GE demonstrates a suppressive effect on both PCNA and GST-positive area ratios [19].

Lung cancer ranks first as the cause of mortality among men and third among women worldwide [20]. Oral administration to nude mice of 25,50 , and $75 \mathrm{mmol} / \mathrm{kg}$ GE inhibits lung cancer cell growth in vivo via an increase of cell apoptosis. This later study shows that GE downregulates HMGCR levels and decreases membrane-bound Ras protein amounts, leading to a decrease in cholesterogenesis. Via the suppressive effect of GE on the mevalonate pathway, cell proliferation is inhibited, and apoptosis is promoted in A549 tumors compared with normal cells where GE did not show any inhibitory effect on cell survival [21].

Oral cancers account for $2-3 \%$ of cancers worldwide, but their survival rate is poor [22]. Thus, it is urgent to search for a novel drug candidate to treat oral cancer. In the 4NQO-induced cancerous mouse model, GE decreased the incidence of oral cancer as a chemopreventive agent. Via the NF- $\kappa$ B pathway, GE reduces the density of immature and mature mast cells and downregulates the expression of downstream inflammatory mediators (e.g., TNF- $\alpha, \mathrm{IL}-1 \beta, \mathrm{COX}-2$, and iNOS) in this model [23]. Another study showed the suppressive effect of GE being effective at a concentration of $200 \mathrm{mg} / \mathrm{kg}$ administered orally in the 4NQO-induced mouse model, which results in the inhibition of the Nrf2 pathway and drug metabolizing enzymes [24].

Pancreatic cancer ranks as the fourth leading cause of cancer mortality in Western countries [25]. Accumulating evidence suggests that natural products exerts a cytotoxic effect on pancreatic cancer cells. In BXPC-3 human pancreatic carcinoma cells, GE significantly suppresses proliferation and induces apoptosis in a dose- and time-dependent manner. Pretreatment with GE for $24 \mathrm{~h}$ before gemcitabine treatment shows a maximal inhibition in BXPC-3 cells. This study also reports that GE suppresses proliferation of prostate cancer cells by inducing ROS production and downregulating phosphorylation of tyrosine kinase [26].
Prostate cancer remains the first cause of mortality in the United States [27]. In prostate tumor cells, GE administration inhibits growth and survival by downregulating the expression of transcription factor E2F8. Via the inhibition of this pivotal cell cycle control factor, the gene expression profile of genes involved in the cell cycle was altered, and the E2F8 inhibition had a suppressive effect on cell growth via inducing G2/M arrest [28].

Skin cancer incidences have been increasing in the last decades [29]. Hence, it is worthy to identify a novel drug candidate to treat skin cancer. Recent reports show that GE significantly inhibits DMBA/TPA-mediated skin tumorigenesis in Swiss albino mice. GE suppresses the Ras/Raf/ERK1/2 signaling pathway and induces apoptosis [30].

\section{Anti-inflammatory and Antioxidant Activities}

Inhibition of the inflammatory response and oxidative stress prevents organs from damage, especially in the brain. The LPO and inflammatory reaction caused by TPA can be significantly decreased by GE. Further investigation demonstrated that GE promotes the metabolism of inflammatory cells, increases GSH content, and stimulates antioxidant enzyme activities. Furthermore, $G E$ exerts an inhibitory effect on the alteration of p38MAPK activity and alleviates the expression change of NF- $\mathrm{BB}$ and COX-2 caused by TPA [31]. Another study also exerted that GE could inhibit inflammation through the inhibition of COX-2 [32]. GE has an inhibitory effect on the pamidronate-induced inflammatory response by stimulating IL-10 production. Also, GE showed no toxin effect on monocytes and did not impact the production of TNF- $\alpha$ [33].

A study tested biochemical parameters and hepatic oxidative stress after GE treatment on Wistar rats and concluded that GE could work as an antioxidant during aromatherapy. GE administration was negatively correlated to the total cholesterol level but there was no difference in glycemia, triacylglycerol protein, and urea levels. The GE-treated rats showed an increase of GSH peroxidase and superoxide dismutase activity, leading to more peroxide accumulation in the liver. GE is able to upregulate the activity of ALT by promoting oxidative stress but has no remarkable effect on AST activity [34]. GE was also shown to protect hamsters from $A D$-induced abnormalities. AD-induced hamsters treated with 
$100 \mathrm{mg} / \mathrm{kg}$ GE showed that the underlying mechanism consists of alleviating the change in the lipid profile and endothelial function marker, promoting antioxidant enzyme activities and abating alterations in the LPO markers and Nrf2 expression. Histologically, GE negatively affected oxidative stress by increasing the activity of Nrf2 [35]. In the meantime, GE could exert anti-inflammatory and antioxidant effects.

Ulcerative colitis severely impairs the quality of life of patients, and no definitive standard of care has been proven effective, to date, for this indication. GE administration decreases the intestinal damage caused by DSS, as reflected in disease activity index scores such as colon length and stool consistency. Pretreatment with GE showed an inhibitory effect on the amount of proinflammatory cytokines and the activity of myeloperoxidase in colon tissue. GE downregulated the expression of downstream target proinflammatory enzymes but upregulated antioxidant molecules: GSH and superoxide dismutase activity were suppressed and LPO and nitrites increases were prevented [36].

GE oral administration was deemed to protect liver tissue from cancer by abating oxidative stress, inflammation, hyperproliferation, and apoptotic tissue damage induced by 2-acetylaminofluorene. Additionally, GE administration restored the damaged structure of the liver tissue. Regarding molecular mechanisms, GE decreased tissue LPO but increased enzymatic activities of catalase, GSH peroxidase, GSH reductase, and superoxide dismutase. GE inhibited the expression of caspase-3, caspase-9, COX-2, NF- $\kappa$ B, PCNA, iNOS, and VEGF, and disintegration of DNA was remarkably reduced [37]. GE could also decrease MetS-induced inflammation and free radical injury by suppressing visceral adiposity and decreasing fasting blood glucose and the glycemic excursion [38].

Another study showed that GE could prevent the ecological disturbances associated with colitis and reduce the inflammatory systemic profile in a colitis mouse model induced by DSS, suggesting that the clinical symptoms of colitis could be improved by GE. Further, the study showed that GE attenuated COX-2 expression in the gut wall [39]. The SCl rat model was used to study the mechanism of anti-inflammatory and antioxidant effects of GE and showed that GE negatively affected spinal cord water content and increased Beattie and Bresnahan scores when rats were treated for 4 weeks with $250 \mathrm{mg} / \mathrm{kg} / \mathrm{d}$ GE. Further, the inhibitory effect of GE on inflammation and oxidative stress was mediated by attenuating the NF- $\kappa$ B and p38 MAPK pathways [40].

\section{Antimicrobial Activity}

Candida albicans is a human fungal pathogen leading to immunocompromized patients and a high rate of mortality [41]. A recent study showed that treatment with GE weakened the activities of albicans and non-albicans species of Candida. Oral administration of GE showed an inhibitory effect on the biofilm formation of pathogenic fungi and hyphal morphogenesis. GE destroyed the cell wall function by downregulating the activity of plasma membrane ATPase and reducing ergosterol levels. GE suppressed fungal expansion by promoting the sensitivity of a calcineurin signaling mutant while enhancing drug resistance to the calcineurin overexpressing strain. Additionally, GE destroyed the mitochon- drial function, broke the iron homeostasis, and mitigated genetic toxicity [42]. Another study showed that the minimum inhibitory concentration of GE is $16 \mu \mathrm{g} / \mathrm{mL}$ against C. albicans and the antimycotic effect of GE is concentration dependent. The morphological interference test demonstrates that GE shows a suppressive effect on pseudohyphae and chlamydoconidia formation [43].

Trichophyton rubrum is one of the most common fungi found in chronic dermatophytosis cases [44]. GE could treat T. rubrum infections of the skin via its antifungal activity. A high concentration of GE could suppress mycelial and fungal growth, and also inhibit conidia germination. GE treated the T. rubrum infection mostly through leakage of the intracellular material and inhibition of ergosterol biosynthesis to destroy the cell wall and cell membrane [45].

\section{Hepatoprotective Effects}

GE could alleviate non-alcoholic steatohepatitis in a methioninecholine-deficient diet-induced rat model through $200 \mathrm{mg} / \mathrm{kg} \mathrm{GE}$ oral supplement. In this model, GE administration showed an inhibitory effect on histological scores, fibrosis, and apoptosis in the liver. On the molecular level, GE inhibits the activities of alanine aminotransferase and aspartate aminotransferase in serum. GE protects the hepatic mitochondrial function through suppression of hepatic mitochondrial ROS, mitochondrial electron transport chain enzyme activity, and mitochondrial DNA content. Further, GE administration attenuates malondialdehyde and 3-nitrotyrosine formation, and inhibits the expression of iNOS and cytochrome P450 2E1 in the liver. Moreover, GE shows an inhibitory effect on inflammation in the liver with the inhibition of TNF- $\alpha$ and IL-6 expression and myeloperoxidase activity [46]. According to hematoxylin and eosin staining and PCR results, GE exhibits a hepatoprotective effect in rats after a $70 \% \mathrm{PH}$, as intraperitoneal administration of GE promoted liver tissue regeneration via improving the expression levels of TNF- $\alpha$ and IL-6. Also, GE remarkably suppressed the ALT level in serum, which regulates the function recovery of liver cells [47]. GE is a natural compound remarkably stimulating liver regeneration as shown in the rat model with a PH that was injected with GE $100 \mathrm{mg} / \mathrm{kg}$. Regarding the mechanism, GE increases the expression of NF- $\kappa B$, TNF- $\alpha$, and IL- 6 mRNA and protein levels, and inhibits HSP27 and HSP60 protein levels [48]. GE could partly restore the oxidative hepatic damage through the administration of a $50 \mathrm{mg} / \mathrm{kg}$ GE intraperitoneal injection in a $\mathrm{H} 2 \mathrm{O} 2$-induced oxidative stress rat model. The mechanism entails the regulation by GE of malondialdehyde and GSH variations caused by $\mathrm{H} 2 \mathrm{O} 2$ and a suppressive effect on hepatic catalase activities [49].

\section{Cardioprotective Effects}

GE could alleviate hyperlipidemia and reduce the incidence of coronary heart disease in an AD feeding mouse model. GE reduces blood fat via the downregulation of HMGCR and the inhibition of lipogenesis. GE suppresses LCAT, decreasing cholesterol esters levels. At the same time, treatment with GE increases the activity of C-reactive protein [50]. GE protects the cardiovascular system from body injury caused by high blood lipids. In particular, GE 
treatment reduces total cholesterol and total triglyceride production in the plasma, and inhibits the biosynthesis of hepatic fatty acids, total lipids, and non-saponifiable lipids. GE increases the uptake of serum LDL by increasing LDL mRNA and VLDL receptor mRNA. Finally, GE suppresses triglyceride synthesis with a decrease of fatty acid synthesis [51]. Over the years, attention has shifted toward GE as a candidate for the treatment of endothelial cell function disorder resulting from a high-fat diet. In addition, GE downregulates serum thiobarbituric acid reactive substances and aortic ROS production. A GE supplement could protect highfat diet-induced vascular endothelial dysfunction by inhibiting NOX-2 expression in the aorta [52]. GE inhibits ROS levels and reduces the injury during myocardial ischemia-reperfusion, and promotes the function and viability of myocardial cells. GE administration in neonatal rat ventricular cardiomyocytes decreased the endogenous production of ROS and exerted a positive modulation of PAMPK levels while attenuating pERK1/2 levels (PAMPK and pERK1/2 are key factors regulating cell survival). Hence, GE showed a protective effect on myocardial cells [53]. GE exerted a cardioprotective effect against cardiac dysfunction induced by diabetes by inhibiting oxidative stress and increasing the marker of oxidative stress 8-isoprostane [54].

\section{Neuroprotective Effects}

In the Drosophila model of ACR-induced nerve injury, GE shows a neuroprotective effect, as mortality caused by ACR is decreased significantly. GE supplementation can attenuate ACR-induced oxidative stress, mitochondrial dysfunction, and neurotoxicity. The mechanism involves the recovery of GSH and total thiol levels with an increase of detoxifying enzymes activities. In addition, coadministration of GE with curcumin showed a negative effect on cholinergic function with a decrease of acetylcholinesterase activity [55]. PD refers to a long-term degenerative disorder of the central nervous system affecting the motor system. GE pretreatment had a protective effect on the nervous system damage caused by PD in a MPTP-induced PD mouse model. GE oral administration ameliorated the neuromuscular disorder via the increase of tyrosine hydroxylase immunoreactive expression and the decrease of $\alpha$-synuclein expression [56]. GE could reduce the motor behavior and neurotrophic factors inadequacy in an MPTPinduced PD mouse model [57]. Another study demonstrated that GE administration in the MPTP-induced PD mouse model regulated the Bcl-2/Bax ratio and inhibited the expression of cytochrome c and caspase-9, resulting in alleviating the neurodegeneration and disordered movements. Cytochrome $\mathrm{c}$ binds to cardiolipin to release it out of the mitochondria and initiate apoptosis. Caspase9 is an enzyme initiating the apoptotic pathway [41]. GE administration exerts an inhibitory effect on the PD clinical symptoms of transgenic PD model Drosophila. GE regulates oxidative stress through a decrease of GSH content and an increase of protein carbonyl content, LPO, and GST activity. GE significantly inhibits $\alpha$ synuclein expression, leading to the attenuation of the PD clinical symptoms in flies [58]. In rats with SCI, GE could attenuate the neuropathic pain and functional impairment through GE administration. Moreover, GE had a positive effect on NeuN-positive cells, but inhibited the expression of glial fibrillary acidic protein in the damaged area and decreased the activity of caspase-3. Further, the study demonstrated that GE treatment in $\mathrm{SCl}$ rats decreased malondialdehyde and 3-nitrotyrosine levels, promoted the protein expression of nuclear factor erythroid 2-related factor 2 and heme oxygenase 1 , and decreased the expression of iNOS. In summary, GE exerts a positive effect on SCI recovery and alleviates neuropathic pain. Hence, GE represents a candidate drug for $\mathrm{SCl}$ treatment [59].

\section{Antidiabetic Effects}

Diabetes is a metabolic disorder presenting with high blood sugar levels and potentially leading to various complications. In an STZinduced diabetic rat model, GE could be used to treat diabetes, as GE administration for 45 days decreased plasma glucose and hemoglobin $\mathrm{HbA} 1 \mathrm{C}$ and could restore the insulin response. The activities of many enzymes involved in glucose production and utilization were restored, leading to an amelioration in carbohydrate metabolism and the restoration of glucose homeostasis [60]. Another study in an STZ-induced diabetic rat model showed that GE treatment has a protective effect on diabetic neuropathy and improved the sensory and motor functions by decreasing enzyme activities (i.e., complexes I-III, succinate dehydrogenase, and citrate synthase) in the sciatic nerve cytosol and selected regions of the brain. GE could alleviate cytosolic calcium levels and acetylcholinesterase activity. Meanwhile, GE could inhibit the protein of carbonyls and nitrites [61]. GE attenuates another diabetic induced complication, i.e., diabetes-induced cardiac functional disorder, by inhibiting oxidative stress and decreasing hyperglycemia. The treatment with GE could increase the cardiac systolic function and recover the diastolic function injured by hyperglycemia. In addition, GE inhibited dramatic oxidative stress by preventing 8-isoprostane increases [62]. GE could attenuate the vascular responsiveness damage of mice with diabetes or MS. Namely, GE administration improved the excessive vasoconstriction induced by diabetes or MS exposed to methylglyoxal in a dose-dependent manner. The study further demonstrated that preincubation with GE ameliorates vasoconstriction. In addition, GE had a suppressive effect on vasoconstriction induced by voltage-dependent and receptor-mediated calcium channels. GE reduces the reaction of the damaged vessels by blocking these types of calcium channels [63].

\section{Other Effects}

GE shows an antiarrhythmic effect on ouabain-induced arrhythmias in mammalian models. GE alleviates ouabain-induced arrhythmias through the downregulation of the contractile force of the heart. GE administration blocks the transient outward potassium $\left(\mathrm{K}^{+}\right)$current (59.7\%), the non-inactivation $\mathrm{K}^{+}$current (39.2\%), and the inward rectifier $\mathrm{K}^{+}$current $(33.7 \%)$, leading to an action potential duration, which increased by $50 \%$. GE also decreased left ventricular pressure (83\%) and the heart rate (16.5\%). GE also prolonged the onset of ouabain-induced arrhythmias by $128 \%$ and decreased the resting tension by $30 \%$ [64].

GE shows excellent anti-ulcerogenic activity on gastric and duodenal mucosa. After GE oral administration to rats, a dose of 
$7.50 \mathrm{mg} / \mathrm{kg}$ GE induces an increase of GSH content and a decrease of myeloperoxidase levels. Moreover, GE reduces the ischemia/reperfusion-induced duodenal ulcerative injury by $71 \%$ and cysteamine-induced duodenal ulcers by $68 \%$. GE protects the gastric and duodenal mucosa by enhancing the activities of protective factors, including endogenous prostaglandins and the nitric oxide pathway. The protection mechanism also involves the increase of mucus secretion with antioxidant properties. GE increases the release of calcitonin gene-related peptide [65]. GE has a protective effect on TNBS-induced colitis injury. Specifically, TNBS-induced colitis rats treated with GE for 11 days showed an improvement of clinical symptoms (e.g., weight loss, colon edema, ulcerative area, and colon/spleen mass indices). GE and/or sulfasalazine could prevent the levels of nitric oxide and lipid peroxide from rising, and restored antioxidant activity in the colitis rat model. On the molecular level, GE inhibits apoptosis and inflammatory cell infiltration by reducing the levels of caspase-3, intercellular adhesion molecule-1, and myeloperoxidase. Intercellular adhesion molecule- 1 is a transmembrane protein, and could stabilize cellcell interactions and facilitate leukocyte endothelial transmigration. Myeloperoxidase oxidation reduces inhibition of apoptosis and inflammation. Conversely, the anti-inflammatory effect of $\mathrm{GE}$ was related to the downregulation of the colon contents of prostaglandin E2 and IL-1 $\beta$ [66].

GE oral administration for 3 weeks showed an antidepressantlike effect on CUMS in rat models and greatly shortened the immobile time in tail suspension tests. More specially, GE decreased CUMS-induced proinflammatory IL- $1 \beta$ levels, resulting in the amelioration of the depressive behavior. GE treatment showed a suppressive effect on NF- $\kappa$ B pathway activation. Furthermore, GE adjusted nucleotide binding and the expression of oligomerization domain-like receptor family pyrin domain-containing 3 inflammasomes [67]. Treatment with GE $(100 \mathrm{mg} / \mathrm{kg}$ b. w) attenuates atherosclerosis-induced tissue fibrosis by hindering tissue remodeling via the suppression of transcription factor NF$\kappa \mathrm{B}$. The weak expression of NF- $\kappa$ B alleviates oxidative stress and inflammatory response, showing a protective effect on tissue fibers [68].

GE could treat Trichomonas vaginalis by killing the parasite. GE destroyed the nuclear membrane and nuclei, leading to chromatin accumulation and a large number of vacuoles appearing in the cytoplasm. Also, ribosomes were reduced, organelles were disintegrated, and the cell membrane was even damaged. Interestingly, GE did not show an inhibitory effect in a time-dependent manner [69].

GE administration at a dose of 100 or $200 \mathrm{mg} / \mathrm{kg}$ alleviated allergic asthma in an ovalbumin-sensitized rat model. The study showed that GE had an inhibitory effect on eotaxin levels in bronchoalveolar lavage fluid and infiltration of eosinophils. Namely, GE intervention decreased TH2 cytokines but stimulated TH1 cytokine interferon in bronchoalveolar lavage fluid. Moreover, GE promoted the expression of Nrf2 protein and intensified Nrf2directed antioxidant pathways (e.g., glutamate-cysteine ligase, superoxide dismutase, and GST). GE also increased the production of GSH [70]. In experimental mice models, GE showed an antinociceptive activity following pain caused by inflammation. The antinociceptive activity was due to a decrease in peripheral nerve ex- citability. Particularly, the behavioral test showed that GE treatment reduced the number of writhes induced by acetic acid. In addition, GE administration reduced mice paw licking time through the regulation of glutamatergic neurotransmission. GE treatment could relieve pain by suppressing neurotransmitters and mediators of inflammation production [71]. Also, GE showed gastroprotective and gastric healing effects on acute ethanolinduced ulcers and chronic acetic acid-induced ulcers [72].

\section{Conclusion}

Recently, pure compounds from natural products are gaining acceptance as potentially promising complementary and alternative medicines for the treatment of various diseases. Generally, single compounds could target DNA, mRNA, protein, and even microRNA. Accumulating evidence in last the decades has indicated that GE is a pure botanical compound without adverse effects, exerting diverse activities by mainly regulating protein expression, suggesting that GE could become a novel drug candidate to treat various diseases. The cytotoxic effect of GE on cancer cells indicates that GE could treat cancer and reduce the mortality of cancer patients. The anti-inflammatory and oxidative effects of GE indicates that GE could protect organ damage and treat ulcerative colitis. The antifungal activity of GE indicates that GE could protect patients from fungal infection. The antidiabetic effect of GE indicates that GE could treat diabetes. The antinociceptive activity of GE indicates that GE could be used as an analgesic in clinical trials. However, anticancer effects of GE should be clarified in vivo in more animal models, and later in human patients, to confirm the inhibitory effect of GE on malignancy. Also, it is worthwhile to explore the molecular basis underlying pharmacological actions (e.g., antimicrobial and antiarrhythmic activities). The lack of information about definitive targets of GE would be a reason against the application of GE in clinical trials.

\section{Acknowledgements}

This work was supported by the National Natural Science Foundation of China NO. 81630101.

\section{Conflict of Interest}

The authors declare no conflict of interest.

\section{References}

[1] van Der Heijden R, Jacobs DI, Snoeijer W, Hallard D, Verpoorte R. The Catharanthus alkaloids: pharmacognosy and biotechnology. Curr Med Chem 2004; 11: 607-628

[2] Zhou J, Wang C, Yoon SH, Jang HJ, Choi ES, Kim SW. Engineering Escherichia coli for selective geraniol production with minimized endogenous dehydrogenation. J Biotechnol 2014; 169: 42-50

[3] Lyu Z, Jain R, Smith P, Fetchko T, Yan Y, Whitman WB. Engineering the autotroph Methanococcus maripaludis for geraniol production. ACS Synth Biol 2016; 5: 577-581

[4] Jiang GZ, Yao MD, Wang Y, Zhou L, Song TQ, Liu H, Xiao WH, Yuan Y]. Manipulation of GES and ERG20 for geraniol overproduction in Saccharomyces cerevisiae. Metab Eng 2017; 41: 57-66 
[5] Shoff SM, Grummer M, Yatvin MB, Elson CE. Concentration-dependent increase of murine P388 and B16 population doubling time by the acyclic monoterpene geraniol. Cancer Res 1991; 51: 37-42

[6] de Cássia da Silveira e Sá R, Andrade LN, de Sousa DP. A review on antiinflammatory activity of monoterpenes. Molecules 2013; 18: 12271254

[7] Solorzano-Santos F, Miranda-Novales MG. Essential oils from aromatic herbs as antimicrobial agents. Curr Opin Biotechnol 2012; 23: 136-141

[8] Carnesecchi S, Bras-Goncalves R, Bradaia A, Zeisel M, Gosse F, Poupon MF, Raul F. Geraniol, a component of plant essential oils, modulates DNA synthesis and potentiates 5-fluorouracil efficacy on human colon tumor xenografts. Cancer Lett 2004; 215: 53-59

[9] Klobučar M, Grbčić P, Pavelić SK, Jonjić N, Visentin S, Sedić M. Acid ceramidase inhibition sensitizes human colon cancer cells to oxaliplatin through downregulation of transglutaminase 2 and beta 1 integrin/FAKmediated signalling. Biochem Biophys Res Commun 2018; 503: 843848

[10] Qi F, Yan Q, Zheng Z, Liu J, Chen Y, Zhang G. Geraniol and geranyl acetate induce potent anticancer effects in colon cancer Colo-205 cells by inducing apoptosis, DNA damage and cell cycle arrest. J BUON 2018; 23: $346-352$

[11] Dong G, Golden SS. How a cyanobacterium tells time. Curr Opin Microbiol 2008; 11: 541-546

[12] Zhang Z, Zhao S, Li X, Zhuo X, Zhang W, Nie Q, Wang S, Yan L, Sun Y. Amentoflavone inhibits osteoclastogenesis and wear debris-induced osteolysis via suppressing NF-KB and MAPKs signaling pathways. Planta Med 2018; 84: 759-767

[13] Shanmugapriya S, Subramanian P, Kanimozhi S. Geraniol inhibits endometrial carcinoma via downregulating oncogenes and upregulating tumour suppressor genes. Indian J Clin Biochem 2017; 32: 214-219

[14] Williams RL, Risau W, Zerwes HG, Drexler H, Aguzzi A, Wagner EF. Endothelioma cells expressing the polyoma middle $\mathrm{T}$ oncogene induce hemangiomas by host cell recruitment. Cell 1989; 57: 1053-1063

[15] Wittig C, Scheuer C, Parakenings J, Menger MD, Laschke MW. Geraniol suppresses angiogenesis by downregulating vascular endothelial growth factor (VEGF)/VEGFR-2 signaling. PLoS One 2015; 10: e0131946

[16] Ferlay J, Soerjomataram I, Dikshit R, Eser S, Mathers C, Rebelo M, Parkin DM, Forman D, Bray F. Cancer incidence and mortality worldwide: sources, methods and major patterns in GLOBOCAN 2012. Int J Cancer 2015; 136: E359-E386

[17] Crespo R, Montero Villegas S, Abba MC, de Bravo MG, Polo MP. Transcriptional and posttranscriptional inhibition of HMGCR and PC biosynthesis by geraniol in 2 Hep-G2 cell proliferation linked pathways. Biochem Cell Biol 2013; 91: 131-139

[18] Queiroz TB, Santos GF, Ventura SC, Hiruma-Lima CA, Gaivao IOM, Maistro EL. Cytotoxic and genotoxic potential of geraniol in peripheral blood mononuclear cells and human hepatoma cell line (HepG2). Genet Mol Res 2017; 16. doi:10.4238/gmr16039777

[19] Sawada S, Okano J, Imamoto R, Yasunaka Y, Abe R, Koda M, Murawaki Y, Isomoto $\mathrm{H}$. Preventive effect of geraniol on diethylnitrosamine-induced hepatocarcinogenesis in rats. Yonago Acta Med 2016; 59: 37-43

[20] Shtivelman E, Hensing T, Simon GR, Dennis PA, Otterson GA, Bueno R, Salgia R. Molecular pathways and therapeutic targets in lung cancer. Oncotarget 2014; 5: 1392-1433

[21] Galle M, Crespo R, Kladniew BR, Villegas SM, Polo M, de Bravo MG. Suppression by geraniol of the growth of A549 human lung adenocarcinoma cells and inhibition of the mevalonate pathway in culture and in vivo: potential use in cancer chemotherapy. Nutr Cancer 2014; 66: 888-895

[22] Parkin DM, Bray F, Ferlay J, Pisani P. Global cancer statistics, 2002. CA Cancer J Clin 2005; 55: 74-108

[23] Madankumar A, Tamilarasi S, Premkumar T, Gopikrishnan M, Nagabhishek N, Devaki T. Geraniol attenuates 4NQO-induced tongue carcinogenesis through downregulating the activation of NF-kappaB in rats. Mol Cell Biochem 2017; 434: 7-15

[24] Madankumar A, Jayakumar S, Gokuladhas K, Rajan B, Raghunandhakumar S, Asokkumar S, Devaki T. Geraniol modulates tongue and hepatic phase I and phase II conjugation activities and may contribute directly to the chemopreventive activity against experimental oral carcinogenesis. Eur J Pharmacol 2013; 705: 148-155

[25] Del Chiaro M, Segersvard R, Lohr M, Verbeke C. Early detection and prevention of pancreatic cancer: is it really possible today? World J Gastroenterol 2014; 20: 12118-12131

[26] Jin X, Sun J, Miao X, Liu G, Zhong D. Inhibitory effect of geraniol in combination with gemcitabine on proliferation of BXPC-3 human pancreatic cancer cells. J Int Med Res 2013; 41: 993-1001

[27] Mirzaei M, Mirzadeh M, Mirzaei M. Mortality rate and years of life lost due to prostate cancer in Yazd province, Iran: A 10-year study. Sultan Qaboos Univ Med J 2017; 17: e424-e429

[28] Lee S, Park YR, Kim SH, Park EJ, Kang MJ, So I, Chun JN, Jeon JH. Geraniol suppresses prostate cancer growth through down-regulation of E2F8. Cancer Med 2016; 5: 2899-2908

[29] Donaldson MR, Coldiron BM. No end in sight: the skin cancer epidemic continues. Semin Cutan Med Surg 2011; 30: 3-5

[30] Chaudhary SC, Siddiqui MS, Athar M, Alam MS. Geraniol inhibits murine skin tumorigenesis by modulating COX-2 expression, Ras-ERK1/2 signaling pathway and apoptosis. J Appl Toxicol 2013; 33: 828-837

[31] Khan AQ, Khan R, Qamar W, Lateef A, Rehman MU, Tahir M, Ali F, Hamiza OO, Hasan SK, Sultana S. Geraniol attenuates 12-O-tetradecanoylphorbol-13-acetate (TPA)-induced oxidative stress and inflammation in mouse skin: possible role of p38 MAP Kinase and NF-kappaB. Exp Mol Pathol 2013; 94: 419-429

[32] Su YW, Chao SH, Lee MH, Ou TY, Tsai YC. Inhibitory effects of citronellol and geraniol on nitric oxide and prostaglandin $\mathrm{E}_{2}$ production in macrophages. Planta Med 2010; 76: 1666-1671

[33] Murbach Teles Andrade BF, Conti B], Santiago KB, Fernandes Júnior A, Sforcin JM. Cymbopogon martinii essential oil and geraniol at noncytotoxic concentrations exerted immunomodulatory/anti-inflammatory effects in human monocytes. J Pharm Pharmacol 2014; 66: 1491-1496

[34] Andrade BF, Braga CP, Dos Santos KC, Barbosa LN, Rall VL, Sforcin JM, Fernandes AA, Fernandes Júnior A. Effect of inhaling Cymbopogon martinii essential oil and geraniol on serum biochemistry parameters and oxidative stress in rats. Biochem Res Int 2014; 2014: 493183

[35] Jayachandran M, Chandrasekaran B, Namasivayam N. Geraniol attenuates oxidative stress by Nrf2 activation in diet-induced experimental atherosclerosis. J Basic Clin Physiol Pharmacol 2015; 26: 335-346

[36] Medicherla K, Sahu BD, Kuncha M, Kumar JM, Sudhakar G, Sistla R. Oral administration of geraniol ameliorates acute experimental murine colitis by inhibiting pro-inflammatory cytokines and NF-kappaB signaling. Food Funct 2015; 6: 2984-2995

[37] Hasan SK, Sultana S. Geraniol attenuates 2-acetylaminofluorene induced oxidative stress, inflammation and apoptosis in the liver of wistar rats. Toxicol Mech Methods 2015; 25: 559-573

[38] Ibrahim SM, El-Denshary ES, Abdallah DM. Geraniol, alone and in combination with pioglitazone, ameliorates fructose-induced metabolic syndrome in rats via the modulation of both inflammatory and oxidative stress status. PLoS One 2015; 10: e0117516

[39] De Fazio L, Spisni E, Cavazza E, Strillacci A, Candela M, Centanni M, Ricci C, Rizzello F, Campieri M, Valerii MC. Dietary geraniol by oral or enema administration strongly reduces dysbiosis and systemic inflammation in dextran sulfate sodium-treated mice. Front Pharmacol 2016; 7: 38

[40] Wang J, Su B, Zhu H, Chen C, Zhao G. Protective effect of geraniol inhibits inflammatory response, oxidative stress and apoptosis in traumatic injury of the spinal cord through modulation of NF-kappaB and p38 MAPK. Exp Ther Med 2016; 12: 3607-3613 
[41] Rekha KR, Selvakumar GP. Gene expression regulation of Bcl2, Bax and cytochrome-C by geraniol on chronic MPTP/probenecid induced C57BL/6 mice model of Parkinson's disease. Chem Biol Interact 2014; 217: 57-66

[42] Singh S, Fatima Z, Hameed S. Insights into the mode of action of anticandidal herbal monoterpenoid geraniol reveal disruption of multiple MDR mechanisms and virulence attributes in Candida albicans. Arch Microbiol 2016; 198: 459-472

[43] Leite MC, de Brito Bezerra AP, de Sousa JP, de Oliveira Lima E. Investigating the antifungal activity and mechanism(s) of geraniol against Candida albicans strains. Med Mycol 2015; 53: 275-284

[44] da Silva BC, Paula CR, Auler ME, Ruiz Lda S, Dos Santos JI, Yoshioka MC, Fabris A, Castro LG, Duarte AJ, Gambale W. Dermatophytosis and immunovirological status of HIV-infected and AIDS patients from Sao Paulo city, Brazil. Mycoses 2014; 57: 371-376

[45] Pereira Fde O, Mendes JM, Lima IO, Mota KS, Oliveira WA, Lima Ede O. Antifungal activity of geraniol and citronellol, two monoterpenes alcohols, against Trichophyton rubrum involves inhibition of ergosterol biosynthesis. Pharm Biol 2015; 53: 228-234

[46] Chen J, Fan X, Zhou L, Gao X. Treatment with geraniol ameliorates methionine-choline-deficient diet-induced non-alcoholic steatohepatitis in rats. J Gastroenterol Hepatol 2016; 31: 1357-1365

[47] Canbek M, Uyanoglu M, Canbek S, Ceyhan E, Ozen A, Durmus B, Turgak $O$. The effect of geraniol on liver regeneration after hepatectomy in rats. In Vivo 2017; 31: 209-213

[48] Ceyhan E, Canbek M. Determining the effects of geraniol on liver regeneration via the nuclear factor $\mathrm{kB}$ pathway after partial hepatectomy. Altern Ther Health Med 2017; 23: 38-45

[49] Ozkaya A, Sahin Z, Gorgulu AO, Yuce A, Celik S. Geraniol attenuates hydrogen peroxide-induced liver fatty acid alterations in male rats. J Intercult Ethnopharmacol 2017; 6: 29-35

[50] Jayachandran M, Chandrasekaran B, Namasivayam N. Effect of geraniol, a plant derived monoterpene on lipids and lipid metabolizing enzymes in experimental hyperlipidemic hamsters. Mol Cell Biochem 2015; 398: 39-53

[51] Galle M, Kladniew BR, Castro MA, Villegas SM, Lacunza E, Polo M, de Bravo MG, Crespo R. Modulation by geraniol of gene expression involved in lipid metabolism leading to a reduction of serum-cholesterol and triglyceride levels. Phytomedicine 2015; 22: 696-704

[52] Wang X, Zhao S, Su M, Sun L, Zhang S, Wang D, Liu Z, Yuan Y, Liu Y, Li Y. Geraniol improves endothelial function by inhibiting NOX-2 derived oxidative stress in high fat diet fed mice. Biochem Biophys Res Commun 2016; 474: 182-187

[53] Crespo R, Wei K, Rodenak-Kladniew B, Mercola M, Ruiz-Lozano P, Hurtado C. Effect of geraniol on rat cardiomyocytes and its potential use as a cardioprotective natural compound. Life Sci 2017; 172: 8-12

[54] El-Bassossy HM, Ghaleb H, Elberry AA, Balamash KS, Ghareib SA, Azhar A, Banjar Z. Geraniol alleviates diabetic cardiac complications: effect on cardiac ischemia and oxidative stress. Biomed Pharmacother 2017; 88: 1025-1030

[55] Prasad SN, Muralidhara. Neuroprotective effect of geraniol and curcumin in an acrylamide model of neurotoxicity in Drosophila melanogaster: relevance to neuropathy. J Insect Physiol 2014; 60: 7-16

[56] Rekha KR, Selvakumar GP, Santha K, Inmozhi Sivakamasundari R. Geraniol attenuates alpha-synuclein expression and neuromuscular impairment through increase dopamine content in MPTP intoxicated mice by dose dependent manner. Biochem Biophys Res Commun 2013; 440: $664-670$
[57] Rekha KR, Selvakumar GP, Sethupathy S, Santha K, Sivakamasundari RI. Geraniol ameliorates the motor behavior and neurotrophic factors inadequacy in MPTP-induced mice model of Parkinson's disease. J Mol Neurosci 2013; 51: 851-862

[58] Siddique YH, Naz F, Jyoti S, Ali F, Fatima A, Rahul, Khanam S. Protective effect of Geraniol on the transgenic Drosophila model of Parkinson's disease. Environ Toxicol Pharmacol 2016; 43: 225-231

[59] Lv Y, Zhang L, Li N, Mai N, Zhang Y, Pan S. Geraniol promotes functional recovery and attenuates neuropathic pain in rats with spinal cord injury. Can J Physiol Pharmacol 2017; 95: 1389-1395

[60] Babukumar S, Vinothkumar V, Sankaranarayanan C, Srinivasan S. Geraniol, a natural monoterpene, ameliorates hyperglycemia by attenuating the key enzymes of carbohydrate metabolism in streptozotocin-induced diabetic rats. Pharm Biol 2017; 55: 1442-1449

[61] Prasad SN, Muralidhara. Protective effects of geraniol (a monoterpene) in a diabetic neuropathy rat model: attenuation of behavioral impairments and biochemical perturbations. J Neurosci Res 2014; 92: 12051216

[62] El-Bassossy HM, Ghaleb H, Elberry AA, Balamash KS, Ghareib SA, Azhar A, Banjar Z. Geraniol alleviates diabetic cardiac complications: Effect on cardiac ischemia and oxidative stress. Biomed Pharmacother 2017; 88: 1025-1030

[63] El-Bassossy HM, Elberry AA, Ghareib SA. Geraniol improves the impaired vascular reactivity in diabetes and metabolic syndrome through calcium channel blocking effect. J Diabetes Complications 2016; 30: 1008-1016

[64] de Menezes-Filho JE, Gondim AN, Cruz JS, de Souza AA, Santos JN, Conde-Garcia EA, de Sousa DP, Santos MS, de Oliveira ED, de Vasconcelos CM. Geraniol blocks calcium and potassium channels in the mammalian myocardium: useful effects to treat arrhythmias. Basic Clin Pharmacol Toxicol 2014; 115: 534-544

[65] de Carvalho KI, Bonamin F, Dos Santos RC, Perico LL, Beserra FP, de Sousa DP, Filho JM, da Rocha LR, Hiruma-Lima CA. Geraniol-a flavoring agent with multifunctional effects in protecting the gastric and duodenal mucosa. Naunyn Schmiedebergs Arch Pharmacol 2014; 387: 355-365

[66] Soubh AA, Abdallah DM, El-Abhar HS. Geraniol ameliorates TNBS induced colitis: Involvement of Wnt/beta-catenin, p38 MAPK, NFkappaB, and PPARgamma signaling pathways. Life Sci 2015; 136: 142-150

[67] Deng XY, Xue JS, Li HY, Ma ZQ, Fu Q, Qu R, Ma SP. Geraniol produces antidepressant-like effects in a chronic unpredictable mild stress mice model. Physiol Behav 2015; 152: 264-271

[68] Jayachandran M, Chandrasekaran B, Namasivayam N. Geraniol attenuates fibrosis and exerts anti-inflammatory effects on diet induced atherogenesis by NF-kappaB signaling pathway. Eur J Pharmacol 2015; 762: 102-111

[69] Dai M, Peng C, Peng F, Xie C, Wang P, Sun F. Anti-Trichomonas vaginalis properties of the oil of Amomum tsao-ko and its major component, geraniol. Pharm Biol 2016; 54: 445-450

[70] Xue Z, Zhang XG, Wu J, Xu WC, Li LQ, Liu F, Yu JE. Effect of treatment with geraniol on ovalbumin-induced allergic asthma in mice. Ann Allergy Asthma Immunol 2016; 116: 506-513

[71] La Rocca V, da Fonsêca DV, Silva-Alves KS, Ferreira-da-Silva FW, de Sousa DP, Santos PL, Quintans-Júnior LJ, Leal-Cardoso JH, de Almeida RN. Geraniol induces antinociceptive effect in mice evaluated in behavioural and electrophysiological models. Basic Clin Pharmacol Toxicol 2017; 120: $22-29$

[72] Venzon L, Mariano LNB, Somensi LB, Boeing T, de Souza P, Wagner TM, Andrade SF, Nesello LAN, da Silva LM. Essential oil of Cymbopogon citratus (lemongrass) and geraniol, but not citral, promote gastric healing activity in mice. Biomed Pharmacother 2018; 98: 118-124 